\title{
Interventional Physiatry: Need of the Day
}

\author{
Rashid MA
}

Physiatry started its journey in the last century with the name of Physical Medicine and Rehabilitation to discharge specialized services to different types of disabled patients to whom conventional medicines have limited role. Apart from teaching specific posture to adopt and to perform definite exercise for a particular problem to get eased and to relief discomfort from physical problems, this speciality would help patients with the aid of heat, electrical equipments and orthoses and prostheses. People were benefited through this service and the specialty got recognition. But the subject did not remain there; rather it flourished like blooming of flower from a bud on addition of new devices and appliances. Everyday, a new weapon is sprucing up the armamentarium of physiatrist also.

Over the last decade, the concept of interventional physiatry has been established to face the medical problems more efficiently and effectively. This got tremendous momentum in the western world especially in the United States. Among the many other conditions, pain, specially the refractory pain of malignancy, rheumatism and neurologic origin are the real challenge for physicians of all specialties. These pains are also a matter of great concern for patients. To handle this pain, the need of intervention was thought of with an aim to hit the culprit; the face- joints, intervertebral disc and lateral races are the common victim of these actions. Epidural- block and facet joint block are measures for relieving pain originated from the spinal cord. Plexus- block and stellate ganglion block are time honored and technically of high quality specialty services. These modalities are applied and proved to be effective in the management of pain due to the involvement of malignant diseases. Peripheral nerve blocking is also proved to be effective in the management of pain to ease our daily activities. Radio-frequency ablation is being adopted as a mean for percutaneous diseconomy in different countries of the world. Ozone therapy is also becoming popular in several countries.

If pain management is the bread and butter for the physiatrist then spasticity management is the soul of the Physiatrist's practice. The role of botulism toxin and phenol block is already well established in PMR literatures. Baclofen pump is another very important tool to counteract spasticity. In addition to that the rehabilitation physicians are confidently tackling different types of endoscopes like cystoscopy in uro-rehabilitation and arthroscopis in tissue injury management. In this country the Physiatrist are already showing commitment in conventional physiatry for decades. In the era of twenty-first century's medical science the physiatrists of Bangladesh are hearing the bell ready to gear up the subject's tool, happy to accept that "Interventional Physiatry: Need of the Day".

Prof. M.A. Rashid, Vice Principal \& Professor, Department of Physical Medicine and Rehabilitation, Shaheed Suhrawardy Medical College, Sher-EBangla Nagar, Dhaka-1207, Bangladesh; Email: drashidmanik@gmail.com; Cell: +8801552432717 